\title{
Rock engineering design - the importance of process, prediction of behaviour, choice of design criteria, review and consideration of risk
}

TR Stacey University of the Witwatersrand, South Africa

\begin{abstract}
In this paper, a thorough design process is described briefly, highlighting the most important steps in the process. Several case studies are described illustrating non-compliance with the design process, for the purpose of emphasising the critical steps in the process. The use of a risk approach in design is dealt with, showing that risk can be a satisfactory design criterion, and that identification of the consequences, and hence quantification of risk, can lead the way creation of value for a mining operation.
\end{abstract}

\section{Introduction}

Mining is an unusual business in which the mining company hardly ever has any control over the price of the product that it produces, the price being determined by market forces. After a feasibility study has been completed and the decision is taken to go ahead with the mining operation, the final design, construction and implementation before the full scale planned production is achieved may take many years -10 to 20 years for a major operation. During this time, the product price has much opportunity to change, up or down. During mining, the product price may also be considered to be dynamic. These are the very high financial risk conditions under which the planning and design of mining operations must be carried out. In addition, safety risks must also be addressed in the mine design.

In reviewing the engineering design process, Bieniawski $(1991 ; 1992)$ quotes the definition of engineering design from the Accreditation Board for Engineering and Technology (1987):

"Engineering design is the process of devising a system, component, or process to meet desired needs. It is a decision-making process (often iterative), in which the basic sciences, mathematics, and engineering sciences are applied to convert resources optimally to meet a stated objective. Among fundamental elements of the design process are the establishment of objectives and criteria, synthesis, analysis, construction, testing and evaluation. In addition, sociological, economic, aesthetic, legal and ethical considerations need to be included in the design process."

If there is a key point that can be identified in this definition, it is that the design must 'meet a stated objective'. This implies that a mining company should have clearly stated design objectives as a component of its operating policy. It is important to note that, as stated by Wong (2002): "Nothing can be $100 \%$ reliable and safe" and "human beings, one day, will invariably make a mistake". There is always some possibility or probability that a failure, accident or fatality will occur. The data in Figure 1 show that there is a probability of loss of life associated with even the most mundane activities. Thorough design will ensure that reliability and safety are at acceptably high levels and that all likely hazards have been satisfactorily addressed. 


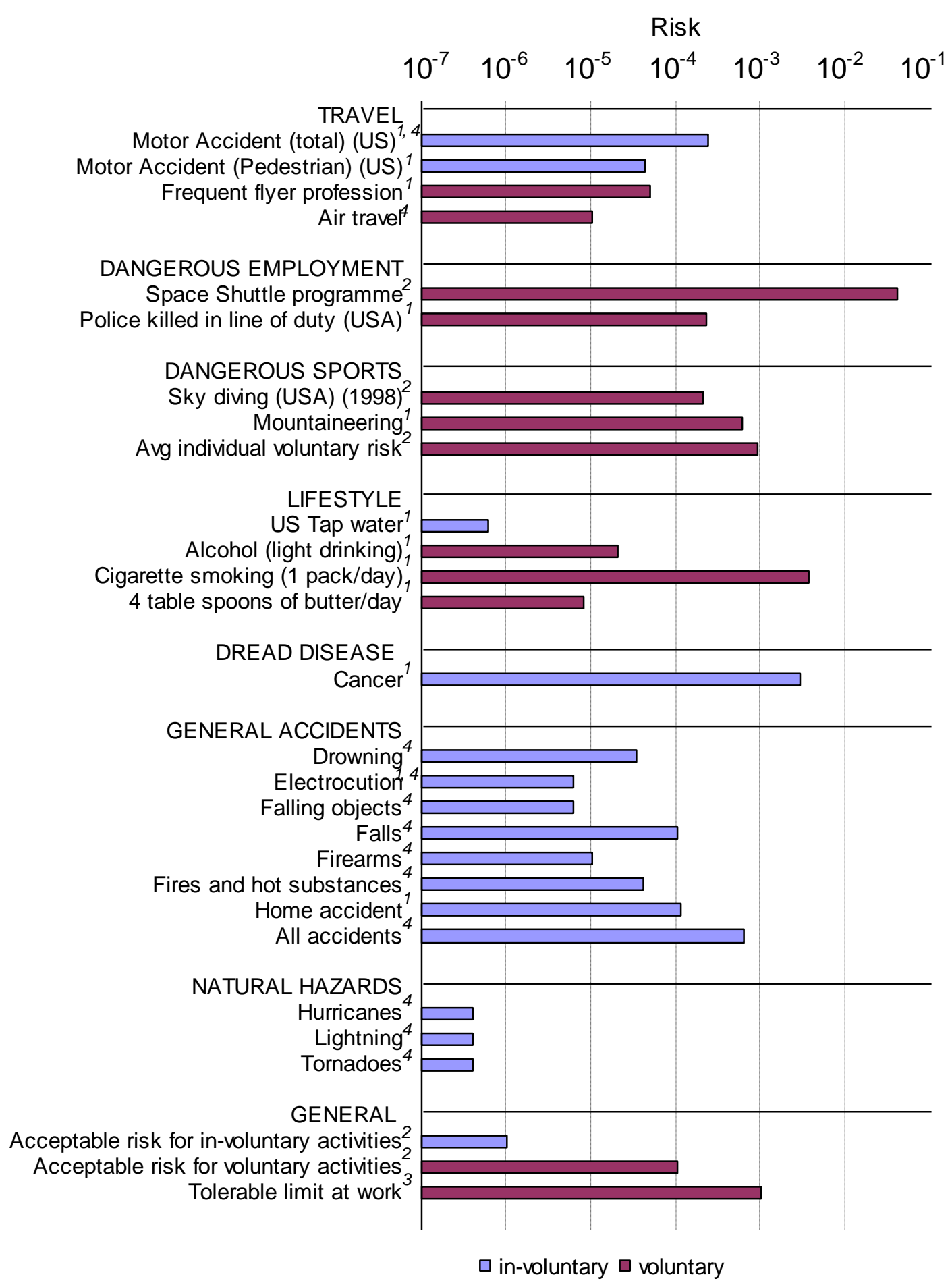

1 Wilson and Crouch (1987); 2 Philley (1992); 3 Hambly and Hambly (1994); 4 Baecher and Christian (2003).

Figure 1 Comparative accident statistics (Terbrugge et al. 2006)

\section{$2 \quad$ A thorough design process}

Engineering design usually involves the development of a 'solution' (the design) to a known 'problem'. There is no unique solution, since there is often a very wide scope in the issues involved in design. The key input to design is required in the early stages of planning a project, when the key thinking and the most important decision-making take place. Front-end loading of projects is essential if they are to meet their desired performance objectives. 
Satisfactory engineering design involves a design process. According to Hill (1983), as discussed by Bieniawski (1988), the design process is "a sequence of events within which the design develops logically, and a process that provides a work plan in the planning of a design programme." Bieniawski $(1991 ; 1992)$ defined a set of six rock mechanics design principles and an associated ten-step design methodology. This methodology represents a thorough design process and can be used as a checklist to ensure that a robust and defensible design has been carried out.

The design methodology corresponding with these design principles is summarised in the ten steps shown in the "circle, or wheel, of design" (Stacey 2006) in Figure 2.

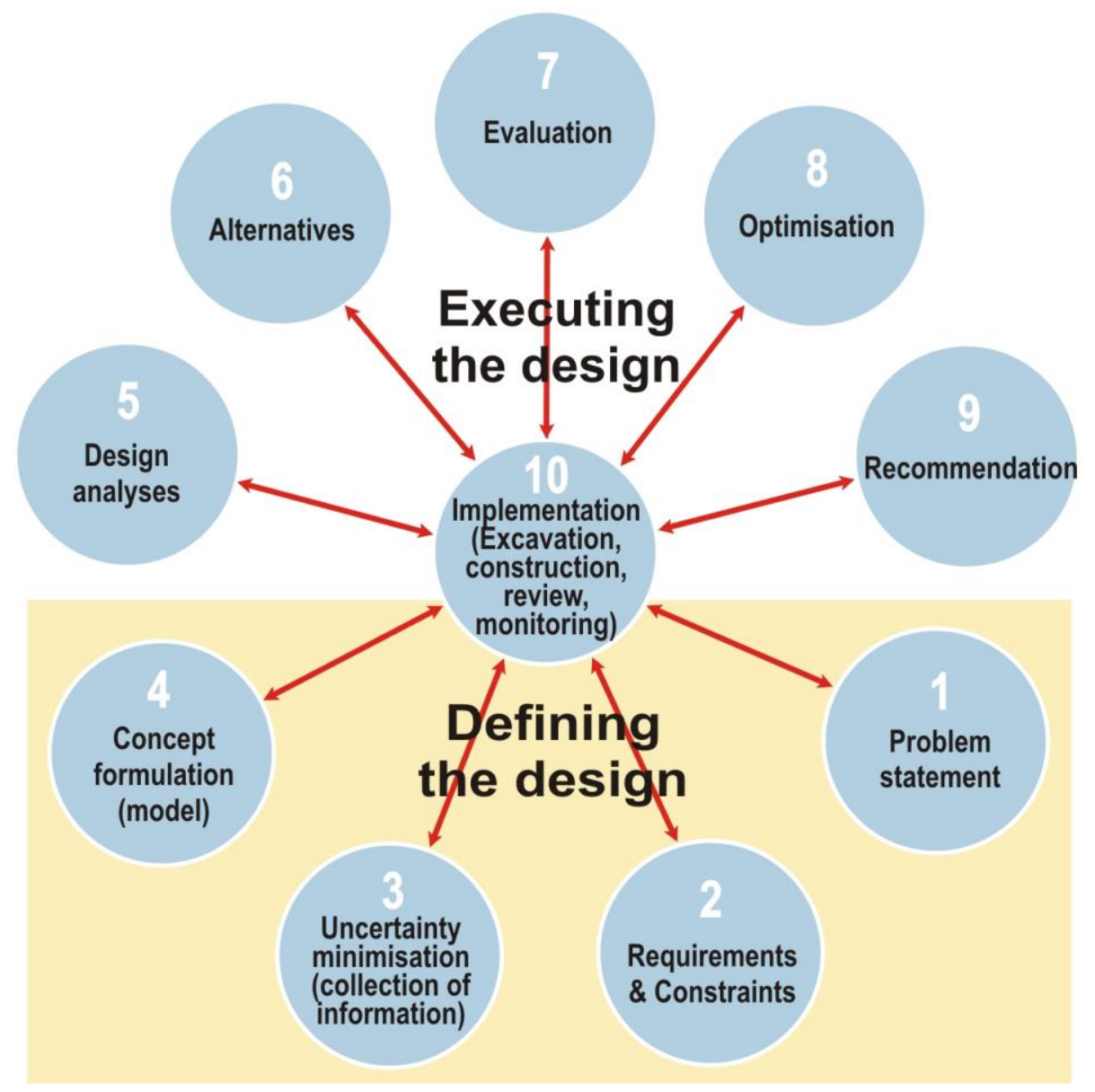

Figure 2 Engineering 'circle, or wheel, of design' (Stacey 2006)

The first two steps, statement of the problem and requirements and constraints, are extremely important steps in that they set out the design objectives, which are fundamental to achieving the desired result. These two steps would therefore include relevant corporate policies that could affect the design. As shown in Figure 2, the engineering design process can be divided into two phases: defining the design (the very important front end loading part), and executing the design (the implementation of the design at various levels of detail). It is the first phase, defining the design, that creates most value for the project, and determines whether the project will be successful or not in returning the expected performance on time and on budget. In the 'defining the design' part of the process (steps 1 to 4), the formulation of the conceptual model (step 4) is probably the most important step in the process. The development of the conceptual model requires an interpretation of the expected behaviour of the excavation and the definition of design criteria. This requires interpretation of the likely mechanisms of failure development, which may involve unusual mechanisms that could have large impacts on behaviour. Examples are buckling, a violent mode of failure not considered in conventional rock failure criteria (Germanovich \& Dyskin 2000); the fan shear failure mechanism in which frictionless shear takes place (Tarasov and Potvin 2013); and cohesion weakening friction strengthening behaviour (Hadjiabdolmajid et al. 2002). 
Review and monitoring are extremely important aspects of design since they allow any faults in the design to be identified at the earliest possible stage. They also show whether actual behaviour corresponds with predicted behaviour. The importance of review and monitoring in any engineering design process is emphasised by the location of this step at the centre of the wheel and by the spokes of the wheel, which link it to all other steps. The implication is that the design must meet the stated objectives at all stages. Independent review during the design process provides a very important control on the quality of the design being carried out. Such an activity should be both informal and formal and could take place at various stages, depending on the magnitude of the design project. The aim of review is to ensure, independently, that the design is robust and that the design objectives are being addressed.

There is often a misconception that analysis is design and many sophisticated analyses, with little underlying validity in terms of input data and failure criteria, are often carried out. It may be observed from the previous steps that analysis, which involves analytical (including numerical), empirical and observational methods, occupies only one step of the overall design methodology. Analysis is a tool to obtain answers to the problem that has been posed. If the input information is inadequate, and/or the conceptual model is incorrectly formulated, the answers obtained from analyses may be scientifically correct, but will be wrong with regard to a valid design. That is, the sophisticated analyses have provided results for the wrong problem.

Minimisation of uncertainty involves investigation to provide input data for engineering design. In mining, it is common that design information is lacking due to a reluctance to incur the costs of obtaining such data. As stated by Wong (2002), "Reliability cannot be predicted without statistical data; when no data are available the odds are unknown." Generally, the greater the uncertainty, the greater the risk. This emphasises the importance of step 3 of the process in generating value for the mining project.

In summary, the above design process serves as a checklist of activities that will ensure that a robust and defensible design has been carried out. Diligent application of this defined process is a form of quality control and will ensure that all aspects that should be taken into account in the design, are taken into account. The similarity between this design process and the strategic planning process developed by Ilbury and Sunter (2005) has been described by Stacey (2006) and demonstrates that strategic planning and design interact closely with each other.

\section{$3 \quad$ Stated objectives of design}

To achieve a satisfactory design, clear definition of the objectives of the design is critical. In a safety context, an objective will be to avoid injuries and fatalities. Since it is impossible to design something that is $100 \%$ reliable and safe (Wong 2002), what reliability is acceptable? Quantified risk has been suggested as a rock engineering design criterion (Stacey et al. 2007); Steffen (1997) and Steffen and Terbrugge (2004) have planned and designed open pit mine rock slopes on the basis of risk. Quantified risk provides the engineer with a tangible basis for design. The negative aspect of this is that it requires a decision as to the 'acceptable risk'. This is a very difficult decision, but the positive aspect is that it also then focuses on value creation for the mine. Risk is dealt with in greater detail in Section 5.

There is nothing new in the consideration of acceptable risk. Geotechnical design in civil engineering is dealt with in the Eurocode 7 standard (now being updated). An earlier version of the code (European Standard 2004) included a requirement for a statement on the level of acceptable risks:

"the assumptions, data, calculations and results of the verification of safety and serviceability shall be recorded in a Geotechnical Design Report. The level of detail of Geotechnical Design Reports will vary greatly, depending on the type of design. For simple designs, a single sheet may be sufficient. The report should normally include the following items, with cross-referencing to the Ground Investigation Report and to other documents which contain more detail: A description of the site and surroundings; A description of the ground conditions; A description of the proposed construction, including actions; Design values of soil and rock properties, including justification, as appropriate; Statements on the codes and standards applied; Statements of the level of 
acceptable risks; Geotechnical design calculations and drawings; $A$ note of items to be checked during construction or requiring maintenance or monitoring.

The Geotechnical Design Report shall include a plan of supervision and monitoring, as appropriate. Items which require checking during construction or which require maintenance after construction shall be clearly identified in the report. When the required checks have been carried out during construction, they shall be recorded in an addendum to the report.

The suitability of the construction procedures and the sequence of operations shall be reviewed against the ground conditions which are encountered and the predicted behaviour of the structure shall be compared with the observed performance. The design shall be assessed on the basis of the results of the inspection and control. If necessary, the structure shall be redesigned.

It shall be checked that the principles used in design are appropriate for the geotechnical features of the ground which are encountered."

This extensive quote has been included here to illustrate the detail that is required in a thorough design. It can be seen that the requirements in this code match very well with the ten step design process described above.

The stated objectives defined in terms of acceptable risk will determine the extent of work involved in the subsequent steps of the design process. For example, in an entry mining method, prediction of the occurrence of rockfalls will be essential; therefore, detailed information on the rock mass will be necessary to allow appropriate design of support. Investigations of the rock mass and considerations of rock mass stability, rock mass behaviour, mechanisms of failure, and stability and support design analyses are likely to be detailed and extensive. If, however, the mining method is a non-entry method, the probability of loss of life in the stope is zero and much less detailed investigation and analysis may be acceptable - the risk is that of loss of, or damage to, equipment.

Wong (2002) stated, "Making things safe and reliable costs money. Engineers will always need to cost the price of failure for comparison." "The latter part of this statement is important - if the cost of failure (direct costs, costs of rehabilitation, lost production, loss of ore etc.) is significant, value may be created by spending the money necessary to ensure safety and reliability. Cost-cutting as a method of improving profitability is common in the mining industry and may be effective as a tactical measure, but in the longer term often results in the destruction of value. Therefore, a strategic approach is preferable. It is to be noted that there can be many combinations of measures to control risk (e.g. extent of investigation data, amount of monitoring, mining method, mechanisation, remote operation, automation etc.). Therefore, large uncertainty in design input data may be countered by conservative design and extensive monitoring to achieve the required level of risk. Alternatively, detailed input data and design with only limited monitoring may achieve the same level of risk. The important result of the design must be to achieve the desired acceptable risk and the best value.

\section{$4 \quad$ Rock and rock mass behaviour, appropriate failure and design criteria, importance of review and monitoring}

Failures in tunnelling and underground mining situations are often given very limited public exposure. This is due to the lack of media access, and often a desire by the project owners to minimise bad news. Conversely, surface failures, be they civil engineering related or in open pit mines, usually receive wide coverage in the media and on the internet, e.g. the slope failures in the Grasberg Pit and, more recently, at Bingham Canyon Mine. In this section, examples will be given from several projects to illustrate, through failures, unexpected behaviour and process shortcomings, the importance of ensuring that a thorough design process is executed. The consequences arising in these projects will also be dealt with briefly to illustrate the consideration of risk. Risk will be dealt with in more detail in a later section. 


\subsection{Rock failure in a dimension-stone quarry}

Although this is not an underground example, it does illustrate particularly the issue of design/failure criteria. The environment of this case is shown in Figure 3, illustrating a small dimension-stone quarry in high quality granite. At the very early stage of mining shown, only limited extraction of rock had taken place, with quarry depths being only a few metres (Figure 4). No detailed mapping, no laboratory testing and no in situ stress measurements were carried out; therefore, this case is purely observational.

The granite is dimension-stone quality, and rock strength is unlikely to be less than $200 \mathrm{MPa}$. The stresses in the rock are unknown, but, taking into account the near surface location and the shallowness of the quarry, are unlikely to exceed say 10 to $20 \mathrm{MPa}$. Realistic values of Hoek-Brown and Mohr-Coulomb strengths for the rock far exceed the likely stresses acting in the rock. Therefore, the conventional methods of prediction of rock failure do not appear to be appropriate in this case. However, after excavation, fractures developed sub-parallel to the surface (Figure 5). These often occurred with considerable violence and, on one occasion, the machine used to drill the closely-spaced vertical holes was reported to have been thrown about $3 \mathrm{~m}$ into the air. Sub-vertical fractures developed subsequently, parallel to the cut face of the quarry, as shown in the Figure 5(b), and it can be seen that they have extended beyond the boundary of the excavated quarry face.

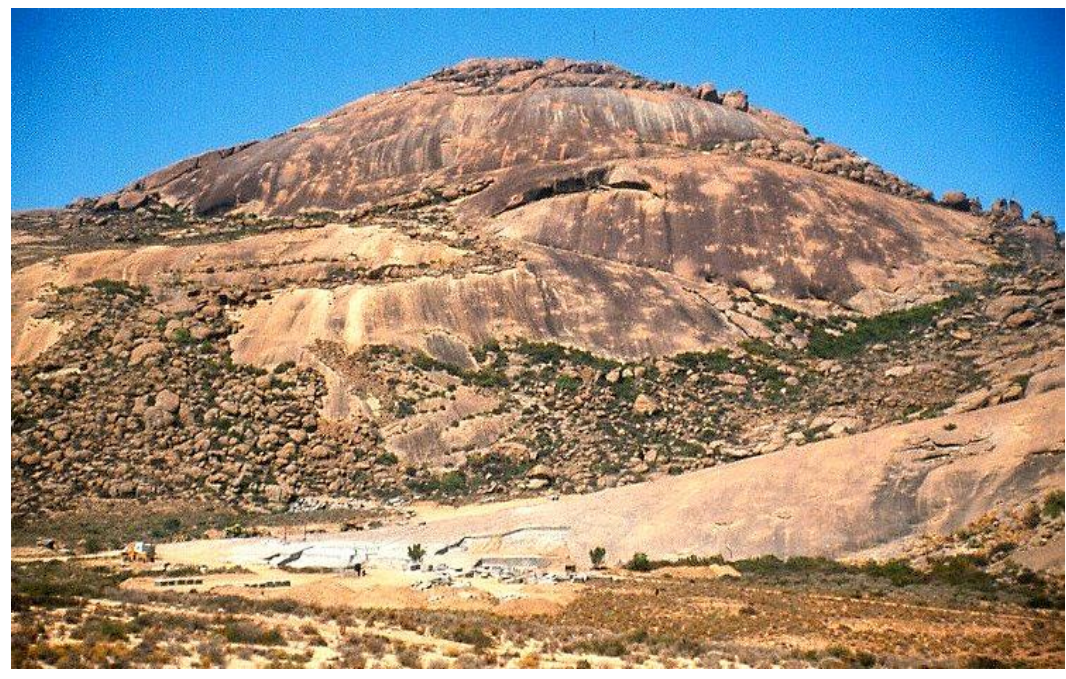

Figure 3 Setting of the dimension-stone granite quarry

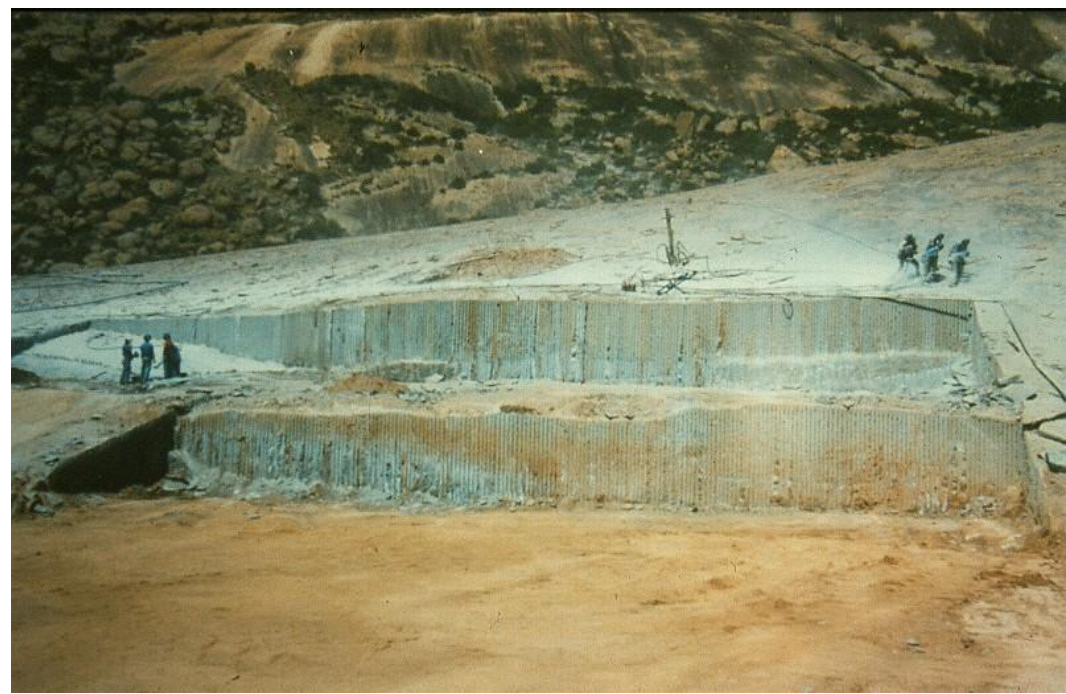

Figure 4 Extent of the quarry 


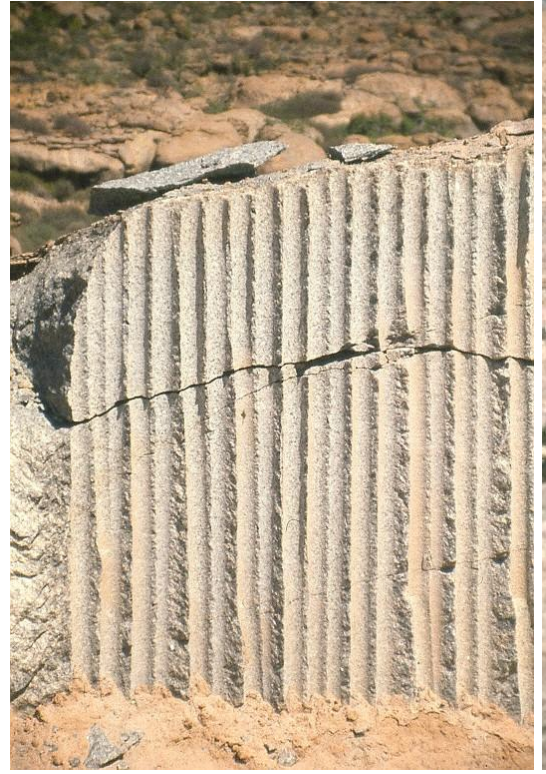

(a)

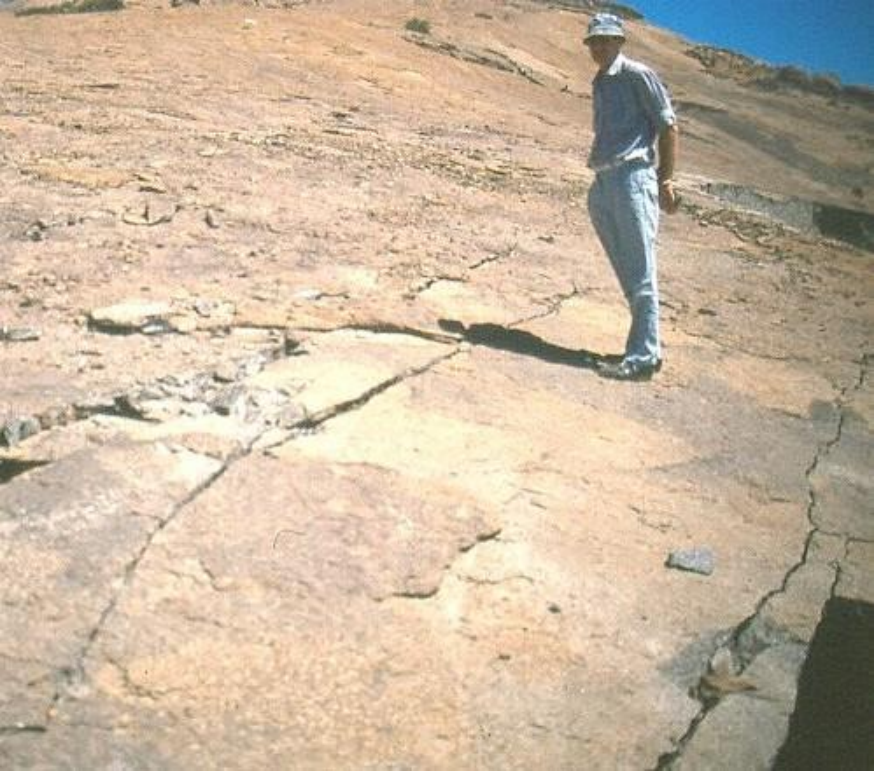

(b)

Figure 5 Stress-induced fractures sub-parallel to the surface and to the quarry face

If one considers strain instead of stress, a compressive stress in the near surface rock will induce extension strains in the rock, normal to the minimum principal stress. This stress is approximately sub-vertical prior to excavation and then also sub-horizontal, normal to the quarry face, after excavation. With compressive stress magnitudes in the range of 10 to $20 \mathrm{MPa}$, the resulting extension strain magnitudes can be expected to be in the range of 100 to $200 \mu$ strain, sufficient to cause the initiation of fractures (Stacey 1981). The determination of strains requires the input of all three principal stresses. From reports of the time of occurrence of fracturing, temperature effects, due to heating during the day and cooling at night, also appear to have had an influence. The measurements of strains that develop in exposed rock surfaces due to temperature variations, carried out by Dünner et al. (2007), indicate that strain magnitudes can be significant. They measured compressive strains of about $200 \mu$ strain sub-parallel to the surface and extension strains of about $100 \mu$ strain perpendicular to the surface. Such temperature-induced strains would add to the strains resulting from the in situ stresses acting in the rock and would clearly contribute to the development of extension fracturing. The development of extension fracturing in the quarry is likely to have led to the formation of incipient slabs, and a buckling mechanism was probably involved in the violent failure that occurred. The consequence of the fracturing was a very large percentage of waste, which was very detrimental to the profitability of the mining operation.

This case study gives an example of a project in which, clearly, there was no rock engineering design input, and therefore no compliance with the design process.

\subsection{Dynamic failure of the roof in a very shallow coal mine}

A case of dynamic failure of roof rock in a coal mine (effectively a rockburst) at a depth of only $22 \mathrm{~m}$, was described by Ortlepp and Moore (1987). Figure 6 shows a photograph of the failure area after it had been re-supported with rockbolts. The geometry of the failure is shown in the plan and section in Figure 7 . The failure took place during top-coaling removal of the top slice of the seam, as can be seen in Figure 7; the primary bord and pillar extraction having been completed some months before. A roofbolt hole was being drilled at the time of the failure. 


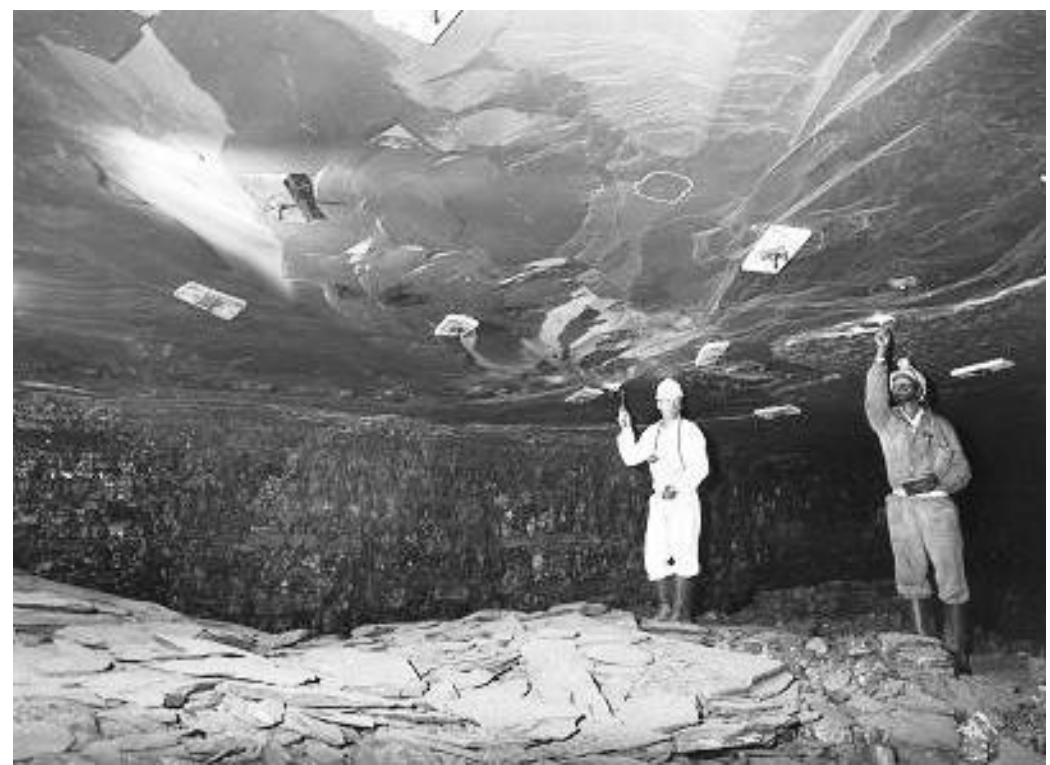

Figure 6 General view of the roof failure

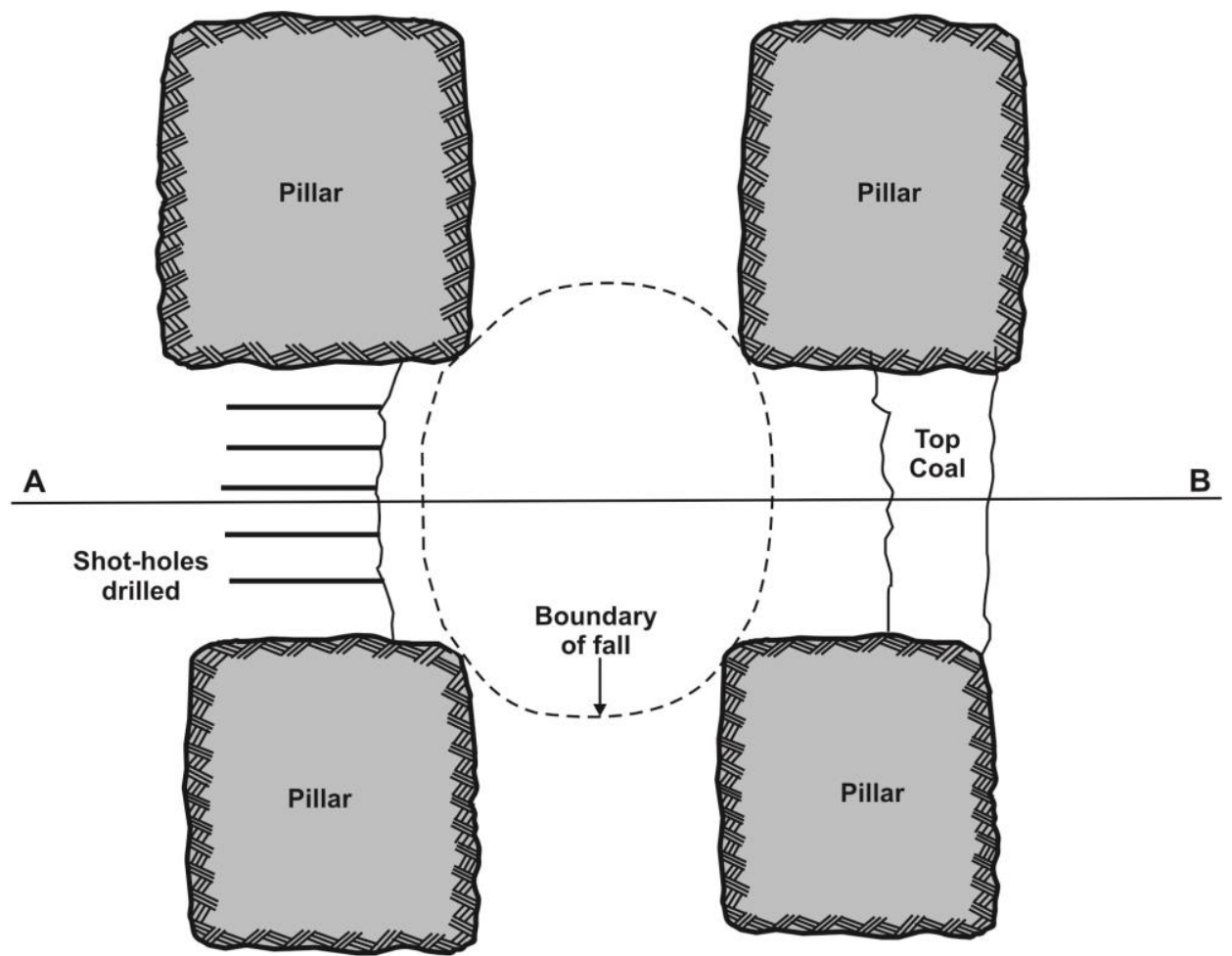

\begin{tabular}{llllll}
0 & 1 & 2 & 3 & 4 & 5 \\
\hline & 1 & 1 & 4 & 5
\end{tabular}

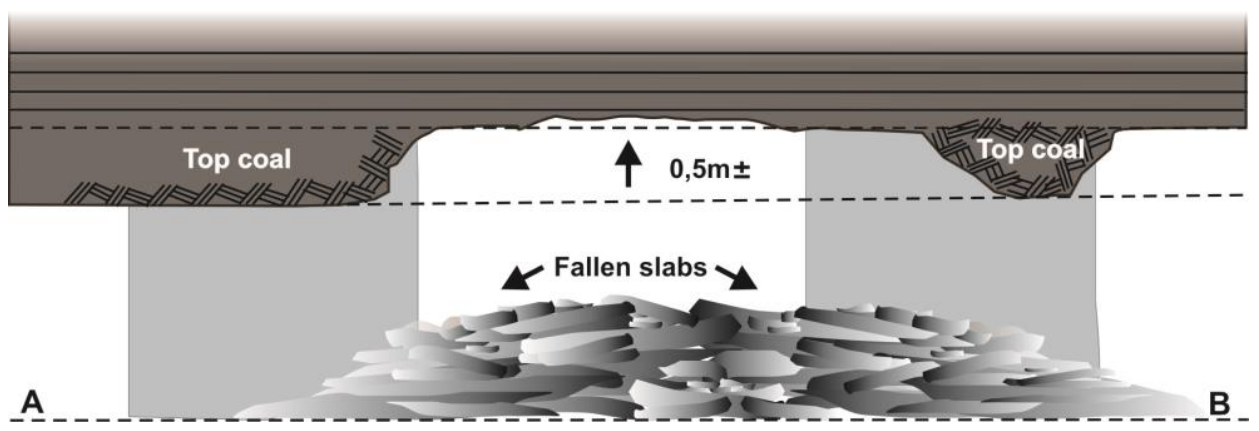

Figure 7 Plan and section of roof failure 
The failure involved the creation of a fracture surface through the intact rock (Figure 8).

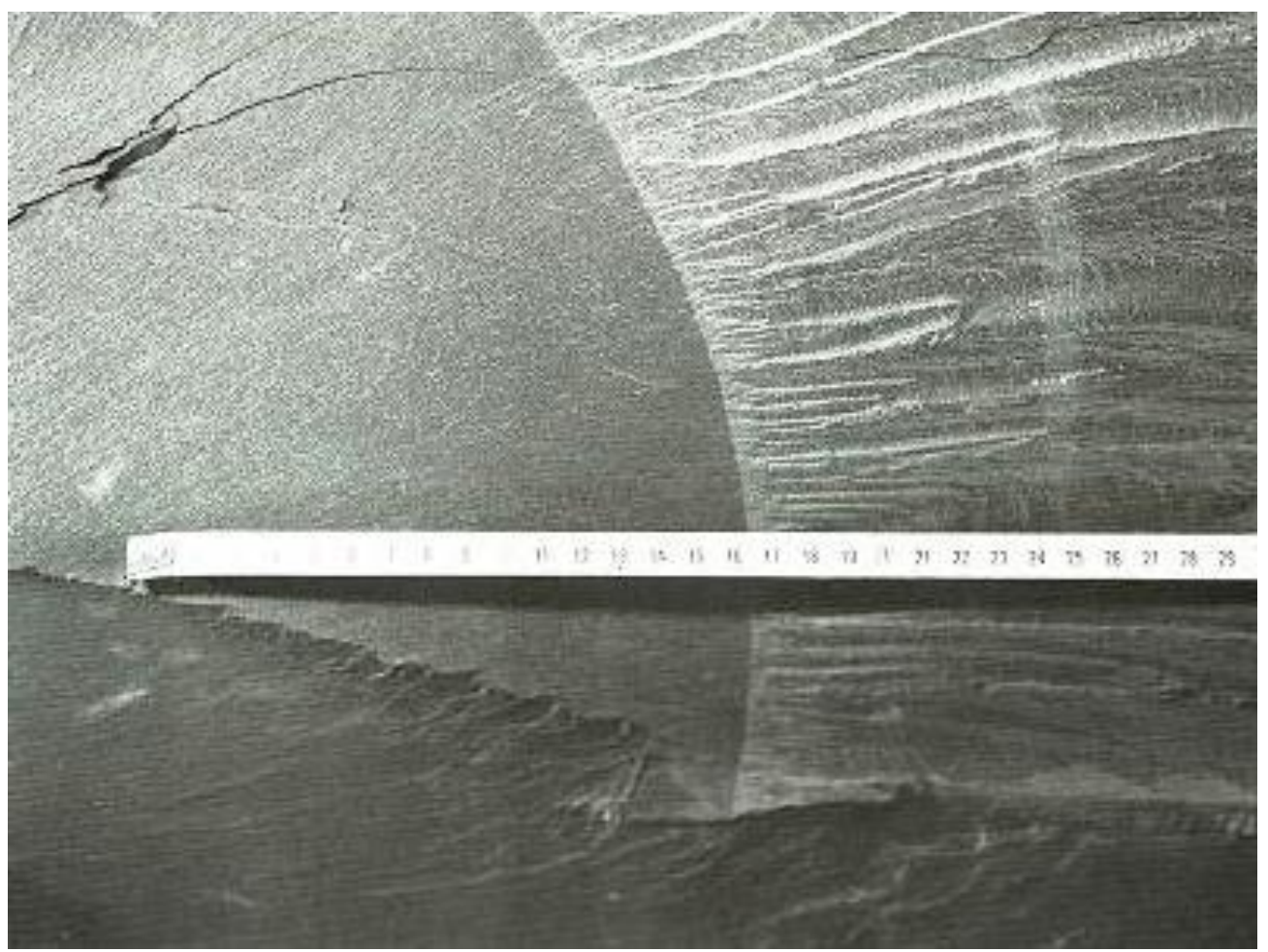

Figure 8 Detail of fracture propagation

The roof rock involved was very fine-grained and anisotropic carbonaceous shale. Its UCS normal to the stratification was about $65 \mathrm{MPa}$ and its tensile strengths normal to the stratification and in the plane of the stratification were, respectively, 2 and $4 \mathrm{MPa}$. The stress level was not measured or known specifically. However, at this depth, the vertical stress could be estimated as $0.5 \mathrm{MPa}$. It is known that the horizontal in situ stress in the coalfields can be significantly greater than the vertical stress (Frith et al. 2002), so an estimate could be $3 \mathrm{MPa}$. This is so significantly less than the UCS of the rock that failure of the intact rock would certainly not be predicted by conventionally used criteria such as Mohr-Coulomb and Hoek-Brown. Normally, in such a bord and pillar environment, one could expect beam bending type behaviour, and the tensile strength in the plane of the stratification could be a criterion. In fact, the failure mechanism appears to have been of a plate buckling mode.

In Figure 8, the detail of a near-perfect arc can be seen, defining the transition from a stable fracture process spreading smoothly at an increasing propagation velocity, to unstable fracturing of a hackly nature. Ortlepp and Moore (1987) studied the mechanics of the failure process and estimated a value of $1.1 \mathrm{MPa}$ for the tensile stress normal to the crack plane at the time the crack front reached the uniform-hackly boundary, which was reasonably close to the tensile strength normal to the stratification. They stated that the fact that there appeared to be several initiating flaws was difficult to explain. However, an explanation might be that there will be a relatively uniform distribution of extension strain in the roof above an intersection, and that the strain levels are likely to be high enough to initiate fracturing. Fractures may therefore have initiated parallel to the stratification at several localised weaker areas.

Similar dynamic failure behaviour was observed in a platinum mine (Figure 9). The dynamic failure was preceded by the occurrence of a substantial amount of microseismicity. 


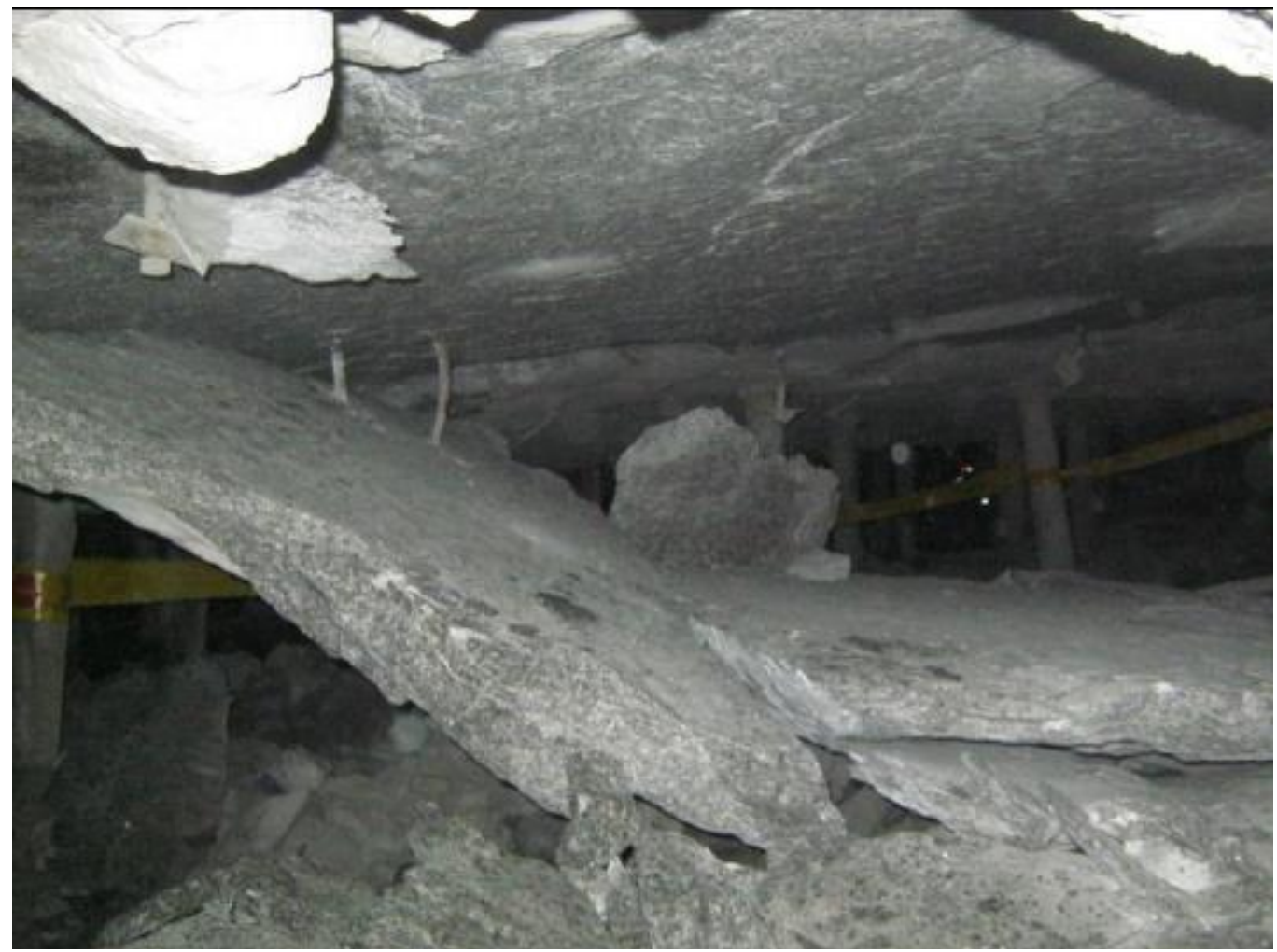

Figure 9 Dynamic roof failure in a tabular platinum mine stope (Stacey \& van Rooyen 2014)

It is also possible that time could have been a factor in both cases - that it was a case of strength decreasing to meet stress (or strain) levels rather than stress increasing to meet the strength; and that incipient slabs or plates by initiation and propagation of fractures in the biaxial stress environment (Sahouryeh et al. 2002). This possibility is supported by the results of Brazilian tensile testing work carried out by Nyungu (2013) on rocks from the platinum mining environment, which showed that long-term tensile strengths are between 60 and $70 \%$ of the tensile strength normally reported from laboratory testing, and could possibly even be less than $60 \%$.

The lesson from this case study is that, during the design process, all possible mechanisms of behaviour need to be considered and their consequences covered in the design. This emphasises the importance of step 4 of the design process - if the conceptual geotechnical model is not correct and complete with regard to rock and rock mass behaviour, it is not possible to carry out a robust design. Further, that the use of conventional rock failure criteria only is not adequate for robust design.

\subsection{Rock fracture and failure around the face of a bored tunnel at great depth}

In the 1970s, a 3.36 m diameter tunnel boring machine was introduced into a gold mine in South Africa, for the purpose of haulage development at a depth of 2,000 m (Stacey \& de Jongh 1977). Shortly after the boring operation commenced, problems were encountered that severely limited the progress of the boring machine. These were as follows (Stacey \& de Jongh 1977):

"spalling of rock from the sidewalls, which in some cases was so extensive that the machine grippers could not reach the sidewalls; fall-out of blocks of rock from the face; abnormally high cutter wear, which resulted from inadequate gripping owing to fracturing of the sidewalls; damage to the belt conveyor caused by sharp pieces of fractured rock; accumulation alongside the machine of rock debris, which was hand lashed and resulted in delays."

After the short length of boring, these problems became such that the machine could no longer continue, and it was removed from the mine. The tunnel produced is shown in Figure 10. Similar problems were experienced with another tunnel boring experiment in a different gold mine (Taylor et al. 1978). 


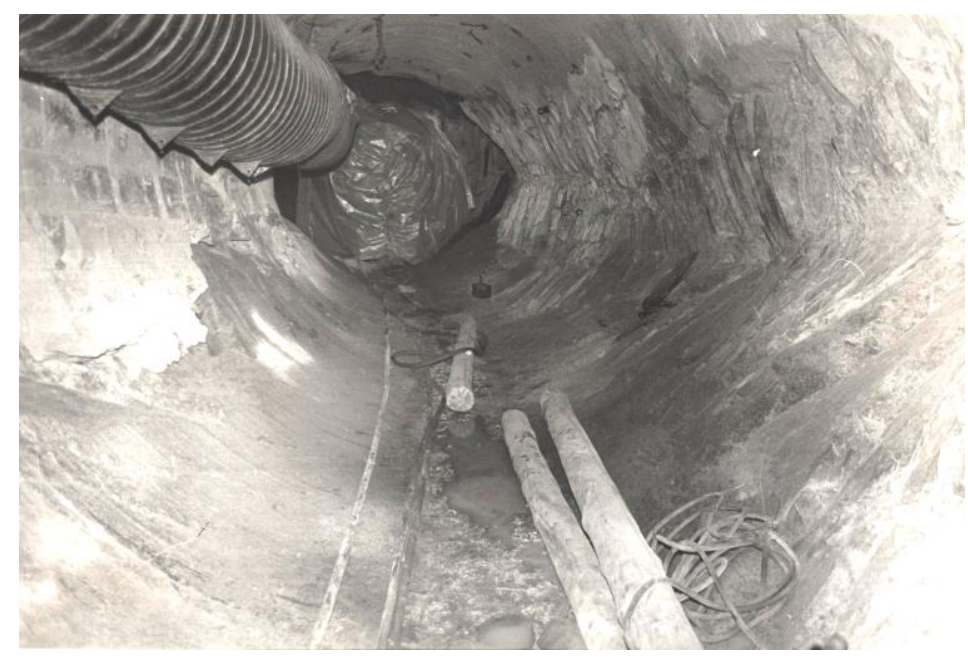

Figure 10 Bored tunnel in a high stress gold mining environment

An after-the-event investigation and analysis of the problems was carried out (Stacey \& de Jongh 1977). This involved three-dimensional stress analyses, and field work to map the extent and orientation of stress-induced fractures around the bore. It was found that the Mohr criterion was inapplicable regarding prediction of both occurrence and orientation of fracturing, and similarly for the Griffith fracture initiation criterion (Stacey 1981). However, an extension strain criterion (then referred to as a limiting tensile strain criterion) very successfully predicted extent and orientation of fracturing at all locations: sidewalls, face, around the corner where face and sidewalls intersect. The following quotes are relevant (Stacey \& de Jongh 1977):

\section{"All the induced fractures observed ... were clearly tensile, showing clean surfaces with no evidence of crushed material due to shearing.}

The fracturing of the sidewalls could be clearly seen by an observer looking back along the tunnel from the face. The fractures in the east sidewall had strike directions in the range of $10^{\circ}$ to $20^{\circ}$ to the tunnel axis, whereas those in the west sidewall were inclined at about $20^{\circ}$ to $25^{\circ}$ to the axis ... The agreement with the theoretically predicted orientations is remarkable. When slabs were prised out of the sidewall it was seen that they were curved with approximately the same radius as the tunnel. This again agrees with ... the criterion of limiting tensile strain.

Slabs could be seen in the sharp corner formed by the face and sidewalls, and were observed to curve very sharply ... around the corner as predicted by the theory.

Barring of the face revealed slabs 10 to $30 \mathrm{~mm}$ in thickness that were curved at the same radius as the cutter head ... as predicted by theory.

The only fracturing that could be observed in the roof was associated with the bedding planes. No fractures attributable to stress could be seen ... again in accordance with the theory."

The design process had not been published at the time of this project; therefore, it is not appropriate to be critical of the process adopted in the decision to implement tunnel boring. However, it is known that there was no rock engineering input prior to the introduction of the tunnel boring machine.

There are two further examples of fracturing around circular tunnels that can be quoted. The first deals with a $5 \mathrm{~m}$ diameter tunnel bored in massive sandstone at a depth of $150 \mathrm{~m}$ (Stacey \& Yathavan 2003). Some months after excavation, sidewall spalling occurred, resulting in a sidewall breakout to a depth of about $400 \mathrm{~mm}$ (Figure 11).

The vertical stress is estimated to have been between 3.5 and $4 \mathrm{MPa}$ and the strength of the sandstone was in the range of 20 to $30 \mathrm{MPa}$. The ratio of the major principal stress to the uniaxial compressive stress is therefore between 0.12 and 0.2 and; under these conditions, failure would not be expected nor predicted using conventional failure criteria. 


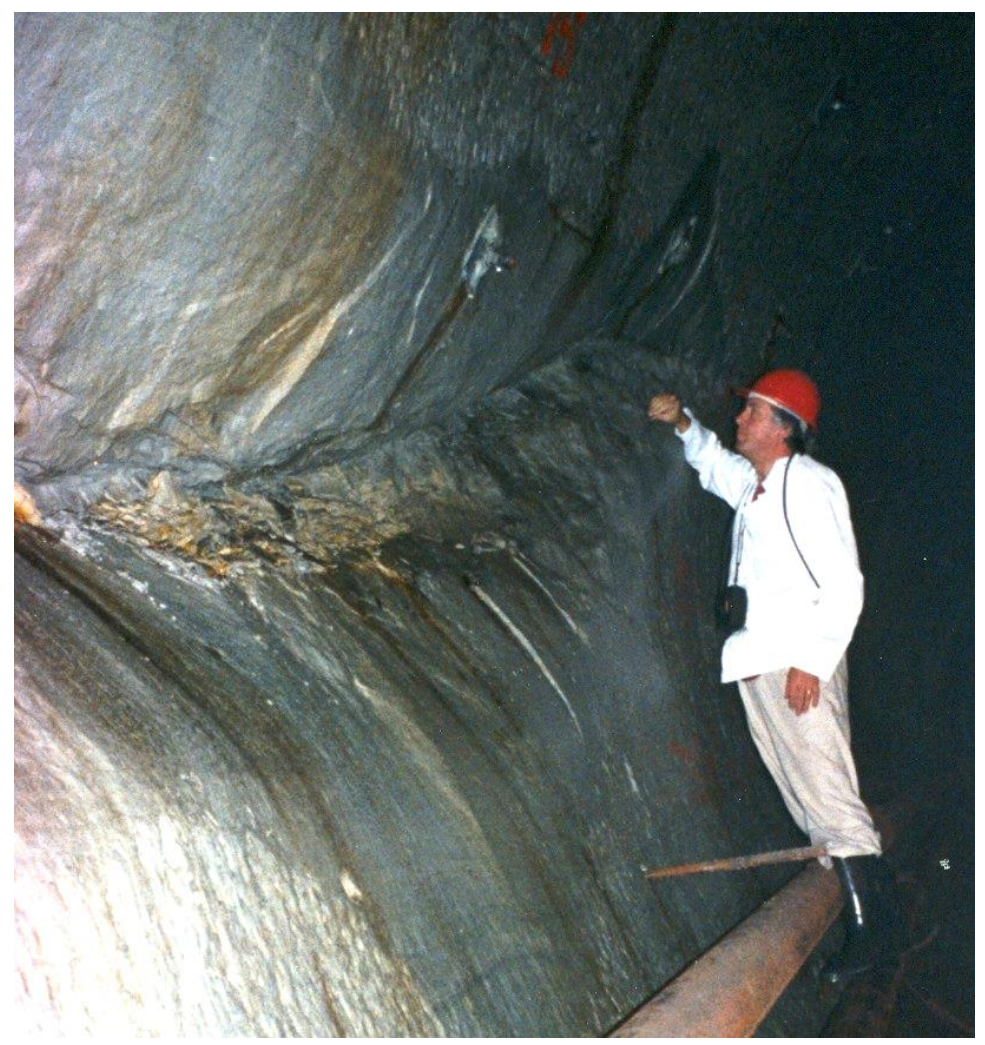

Figure 11 Stress-induced breakout in a bored tunnel at a depth of $150 \mathrm{~m}$

The second case is the well-published Atomic Energy of Canada Limited tunnel in Canada (Martin et al. 1997). This is a high quality case study since parameters are well known: the rock strength parameters and the in situ stresses, as well as the history of fracture and failure development. Breakout development has been modelled using alternative failure criteria. The observed breakout geometry was matched well using the cohesion weakening friction strengthening criterion (Hadjiabdolmajid et al. 2002), but this also indicted failure on the sub-horizontal axis, which did not occur. The Mohr-Coulomb prediction was completely incorrect. Wesseloo (2000) modelled the development of the breakout with FLAC, using an extension strain criterion. Failed zones were nulled to simulate fallout of spalling rock. The predicted development of the breakout eventually stabilised, and its final geometry matched the observed geometry perfectly, as shown in Figure 12. Predicted failure using the three criteria are summarised in Figure 13.

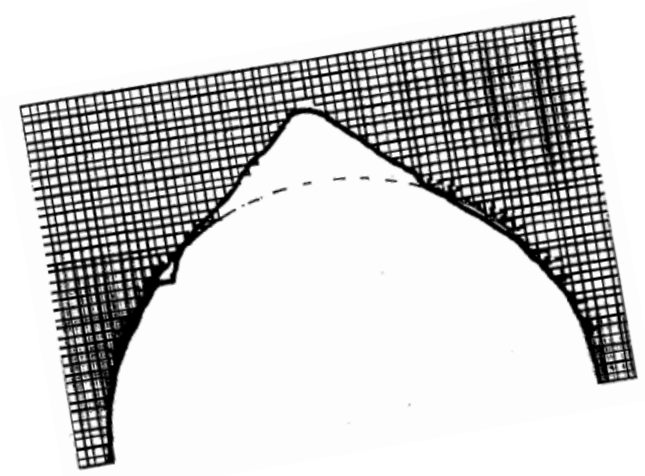

Figure 12 Prediction of AECL tunnel breakout using an extension strain criterion (Wesseloo 2000) 


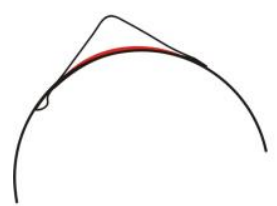

A

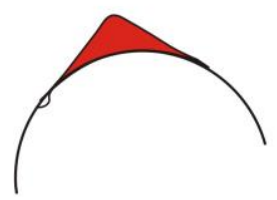

C

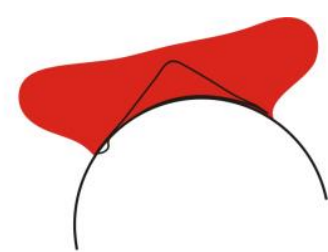

B

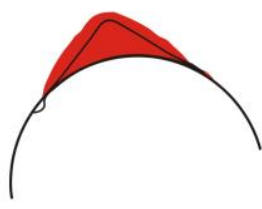

D

Figure 13 Extent of failure predicted by alternative criteria: (A) observed geometry; (B) Mohr-Coulomb; (C) extension strain; and (D) cohesion weakening friction strengthening

This case shows the importance of using an appropriate failure criterion that corresponds with the expected failure mechanism, and secondly, the importance of the fourth step of the design process. Note that, if the purpose of the analysis was to determine the required length of rockbolts or cables, then approaches B, C or D in Figure 13 would be adequate. However, if the requirement was the prediction of the extent of failure, then $C$ or $D$ is satisfactory. If the prediction of the orientations of the fracturing is required, then only $\mathrm{C}$ is satisfactory.

\subsection{Design of orepasses}

Although rock passes for ore and waste in mines are extremely important components of a mine's infrastructure, they are usually given very little attention with regard to strategy and design (Hadjigeorgiou \& Stacey 2013). To quote from this reference:

"This paper ... reaches the disappointing conclusion that there is an absence of strategy in orepass planning, design, and management. Consequently, it is not surprising that a large number of operations experience various problems of varying degrees of severity and economic consequences."

Orepass designs are often simply lines on engineering drawings without any geotechnical basis. There is usually no geotechnical information associated with passes and, commonly, no documentation on the condition of the pass until a problem occurs. As an example of this situation, an investigation was carried out into the performances of deep level orepasses, in which data were sourced from more than 200 individual passes in eight mines. The investigation showed that less than $50 \%$ of the passes were in good condition, 33\% in a poor condition, $16 \%$ abandoned, and 3\% rehabilitated (Joughin \& Stacey 2005). The quality of data available on the passes was very poor. It is common that there is often no geotechnical information available at design stage (probably no definition of objectives in step 1 of the design process, and certainly contradiction of step 3, the minimisation of uncertainty, which then naturally limits the validity of any step 4 considerations). This is perhaps understandable since, in a new mining environment, decisions on orepass locations and orientations have to be made well before satisfactory geotechnical information is available. However, this situation might change if the financial costs of overpass problems were to be taken into account by mines. Such problems include hang-ups and their clearing, pass rehabilitation, pass replacement and, perhaps the most important consideration of all, the loss of production associated with the problems.

In the above investigation of pass performance, rock mass quality was estimated and correlated with the extent of breakouts (referred to as 'dog ears') (Figure 14). 

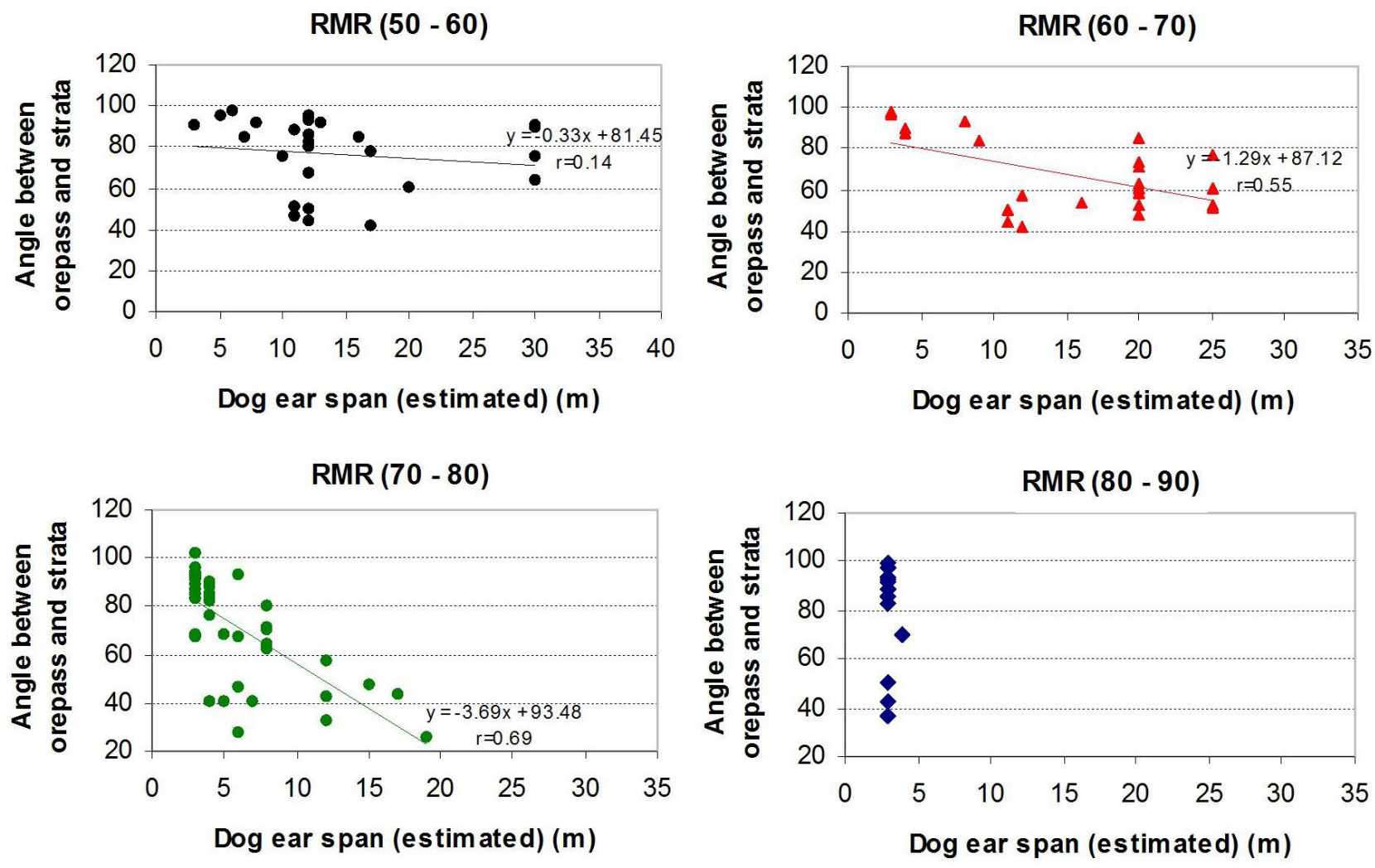

Figure 14 Relationships between rock mass quality, pass orientations relative to strata dip, and breakout spans (Joughin \& Stacey 2005)

The validity of the data was assessed using a discrete fracture network approach (Stacey et al. 2005) (Figure 15), and gives some confidence in its usefulness.

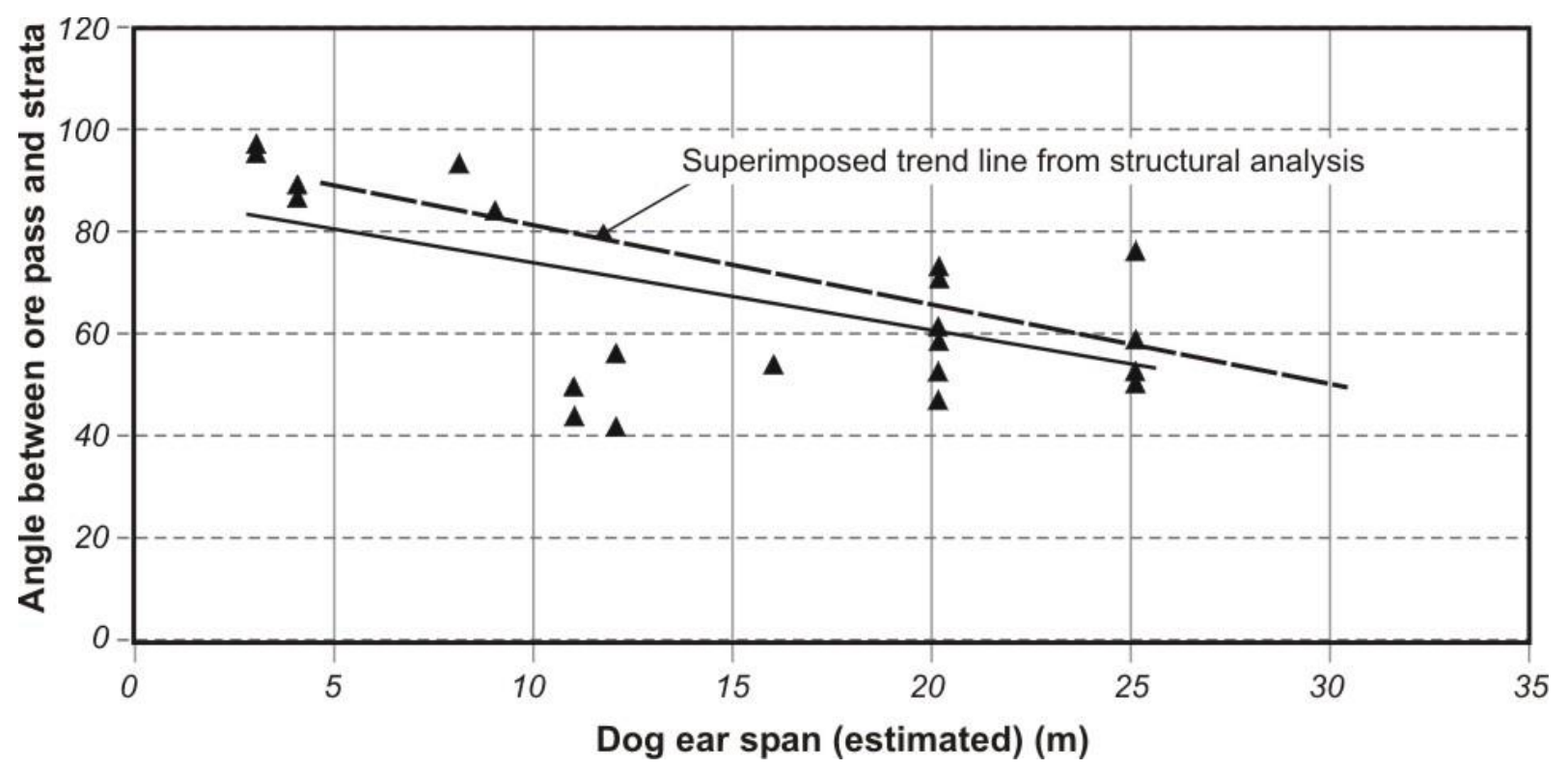

Figure 15 Estimated breakout spans versus angle between pass and strata for rock mass quality RMR 60-70 (Stacey et al. 2005)

Therefore, in spite of the poor quality of the data and in the absence of better information, it does appear that they could be useful for empirical prediction of pass performance in the deep level gold mining environment, albeit with substantial variability. 


\subsection{Failure of support in a rockburst event}

The tunnel support system shown in Figure 16 (Stacey \& Rojas 2013) consists of concrete panels, each panel being retained against the rock surface by fully-grouted cables. After a rockburst, it was found that panels had been ejected from the sidewalls, causing significant damage to the support system. This represents a failure of the support design, resulting in an unsupported rock surface, a potentially hazardous situation.

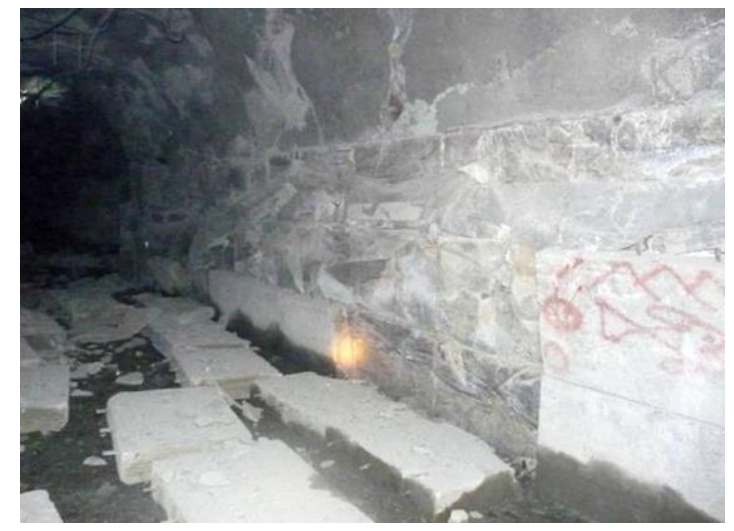

Figure 16 Concrete support panels ejected during a rockburst event (Stacey \& Rojas 2013)

To ensure safe, stable working areas it was necessary to implement remedial measures at short notice. The solution adopted was the installation of steel wire ropes, wrapping over the panels, with the ends of the ropes being grouted into boreholes drilled through the panels. This remedial support design is illustrated in Figure 17, the photograph showing the support prior to its being sprayed with shotcrete protection against mechanical damage. Owing to the geometry of the remedial support ropes, they are colloquially referred to as staples. Such staples provide the containment support to the panels, preventing them from being thrown off in a rockburst event. The wire ropes need to be loose enough to perform in a secondary mode - to catch the ejected panels but not to be part of the primary support system.

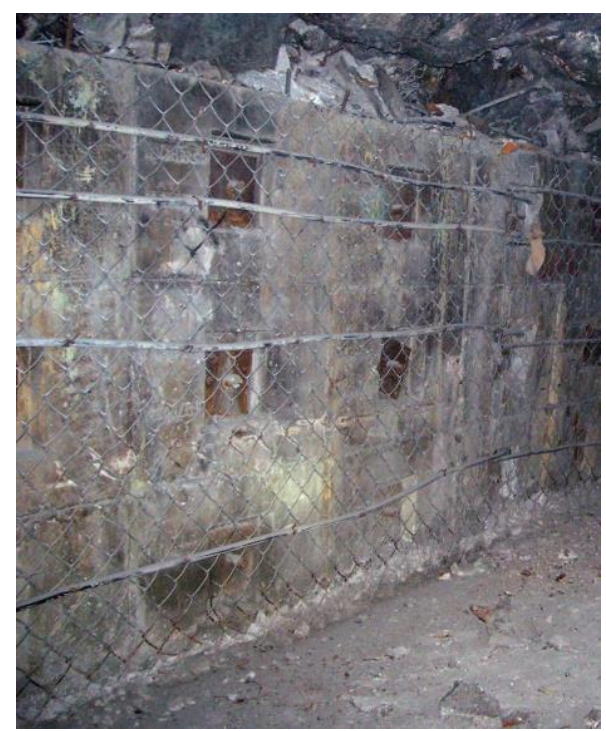

Figure 17 Remedial staple support with wire ropes (Stacey \& Rojas 2013)

The concrete panel support shown in Figure 16, a satisfactory design in static conditions, could be considered to be an inappropriate support system for dynamic, rockburst conditions. Concrete panels retained by fully-grouted cables represent a rigid support system. Such a rigid system is contrary to the commonly understood rockburst design requirement of compliant, yielding support systems that can absorb energy during deformation but at the same time maintain their load carrying capability. Therefore, 
this rock support design did not satisfy the design process: it did not meet the design objectives to provide adequate support under static and dynamic loading; the conceptual geotechnical model was wrong and failure criteria inappropriate. The review and monitoring aspect of the design process was successful in that a revised design was quickly implemented.

The negative perception associated with the original support design is countered by two very positive observations. Firstly, the rock surfaces that were behind the failed panels were not displaced and appeared undamaged by the rockburst. Therefore, the rock was protected from damage. Secondly, the performance of the new, remedied, support system under rockburst loading has already been tested in practice, since such support has been subjected to actual rockbursts in the mine. Under such conditions, it has proven to be capable of preventing ejection of the concrete panels, hence confirming that it is a successful support system for rockbursting conditions. The panels represent sacrificial support components; their ejection, which would be the observable rockburst damage, is prevented by the staples in their secondary support capacity. Most importantly, the rock is left apparently undamaged, therefore ensuring that the rock mass retains its coherence and that the excavation maintains its stable state. The magnitudes of seismic events to which this support system have been exposed are in the same range as the events that caused the ejection of panels, prior to the remedial support.

\section{$5 \quad$ Consideration of risk}

Risk considerations take into account the occurrence of events and the consequences of those events. In this context, risk is defined as the product of the probability of occurrence of an event (usually unwelcome) and the consequences of occurrence of that event. The risk is usually quantified in financial terms. A mining company's strategic planning process should identify strategies that are acceptable to the mining company, including the levels of acceptable risk. These strategies should then naturally be expected to form the bases of the criteria for all mine design and operation activities, and would be important inputs into the design process dealt with earlier.

The traditional non-risk design approach involves collecting the geotechnical data that could be required for design of an underground excavation to an appropriate confidence level; designing to a Factor of Safety or probability of failure (POF) defied by company policy; providing the resulting excavation and rock support specification to the mine planners for their design and economic calculations; and applying monitoring procedures to determine the adequate performance of the supported excavation according to the expectations of the rock engineer. In contrast, the risk/consequence analysis process reverses the traditional design approach (Stacey et al. 2007) and instead uses the following design process: determine the risk criteria for each consequence at the outset; establish best practice management tools for the supported excavation performance required; calculate the required POF for rock support design; perform the excavation and rock support design to the required reliability at the required level of design; collect geotechnical data appropriate for the required level of design confidence.

The reversal of the traditional approach to underground excavation and rock support design has the objective of delivering a design in conformance with the business requirements of the company. This requires that business objectives have to be decided up front, which is consistent with both the strategic planning process and the design process, in which the required risk profiles would be defined as performance objectives in the design process.

The risks associated with a stope collapse can be categorised by the following consequences: injuries or fatalities; damage to equipment; economic impact on production; force majeure (a major economic impact); industrial action; public relations, such as stakeholder resistance due to social and/or environmental impact. Three of these six consequences are economically related, although on different scales. These differentiated scales equate to the acceptable risk (or the risk criterion) that would apply to each case. Each of the risks quantified must be acceptable to the mine owners.

A risk evaluation process for an underground stope is illustrated in Figure 18 showing a fault tree for calculating the POF, the logic diagrams (event trees) for determining the risk exposure that follows from the 
selection of a specific stope support design and the evaluation of the risks against the specified risk criteria. The risk/consequence analysis has been described in some detail by Terbrugge et al. (2006).

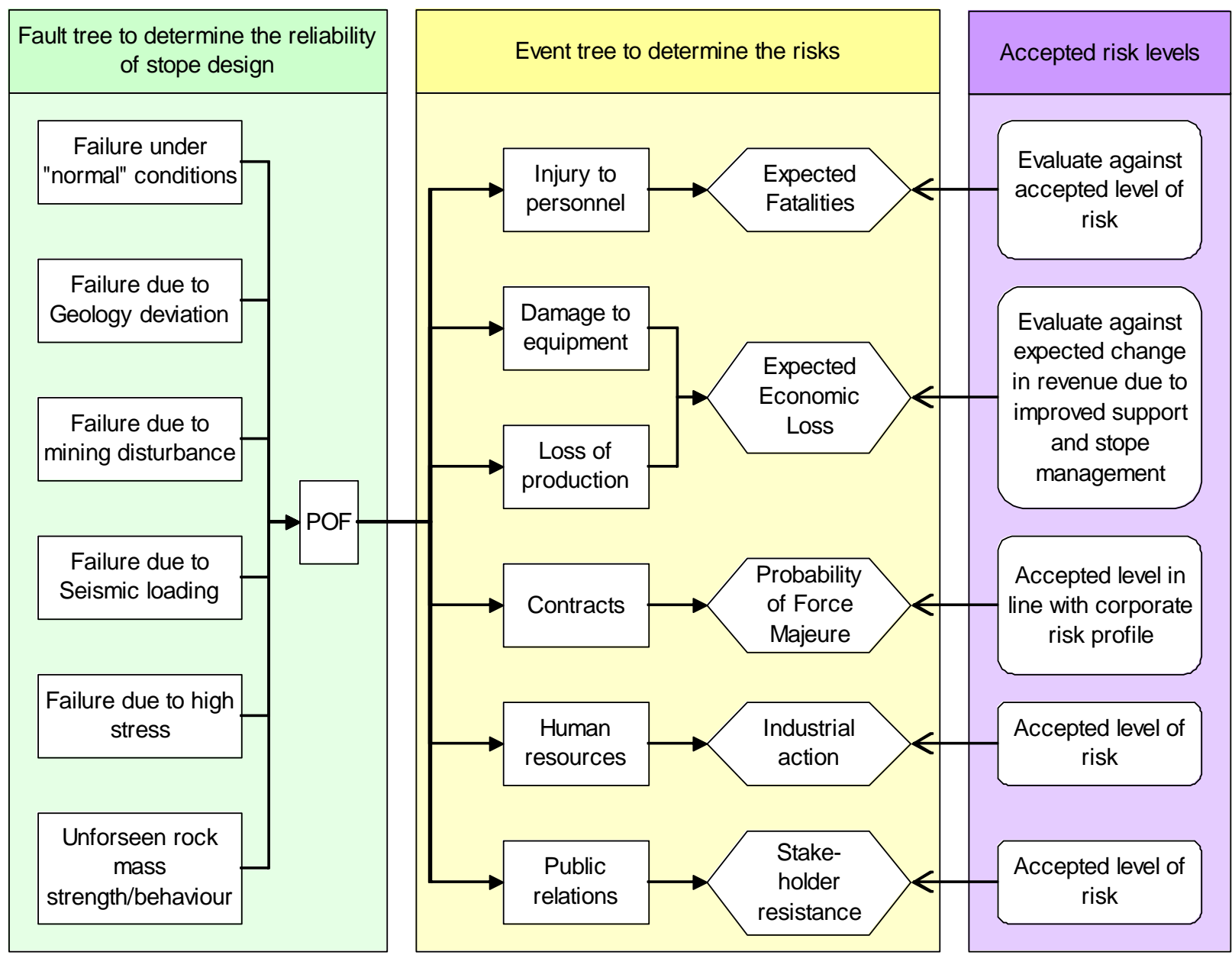

Figure 18 Risk evaluation process (Terbrugge et al. 2006)

Safety risk can be evaluated using the event tree model shown in Figure 19. The potential for injuries and fatalities can be managed by instituting strict stope management procedures, hence changing the probability of a fatality. Without such procedures, the risk to personnel is dictated by the effectiveness of the stope support. The implementation of the stope management procedures, as indicated in Figure 19, shows how risk could be reduced without increasing the support installed to reduce the POF. For example, improved effectiveness of the monitoring system and an improved evacuation procedure would substantially reduce the probability of annual occurrence of an accident. A similar event tree can be used to assess the risk of damage to, or loss of equipment.

In addition to the safety risks posed by rockfalls, they can result in economic consequences. An example of an event tree for the economic impact of a significant collapse is shown in Figure 20. A major economic impact needs to be defined to quantify the risk. This could be force majeure, as illustrated in Figure 18, or simply the closing down of the mining operation. 


\section{Compare with acceptable risk level}

Probability of fatality $0.07 \%$

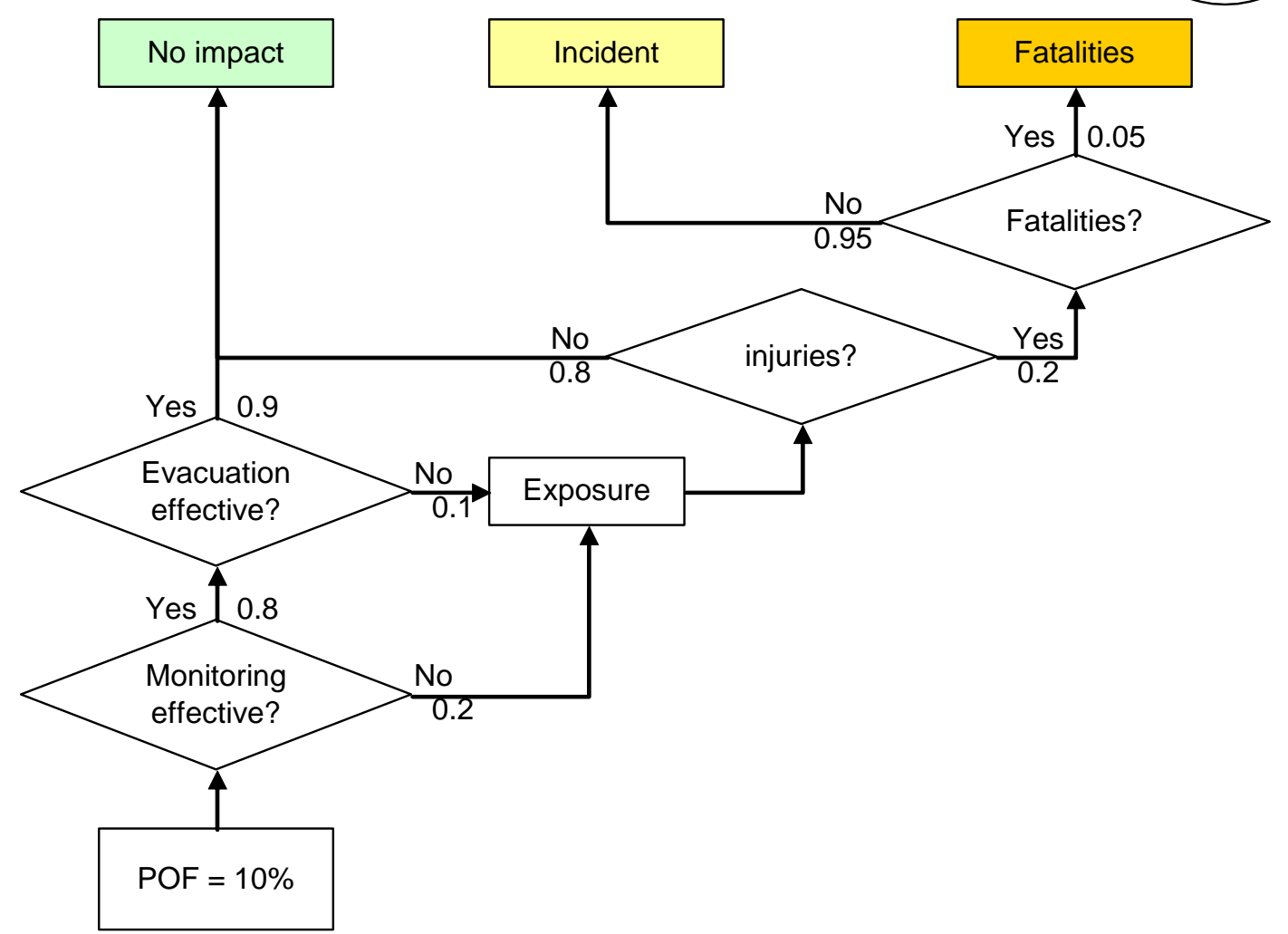

Figure 19 Simplified event/consequence tree for injuries/fatalities (Terbrugge et al. 2006)

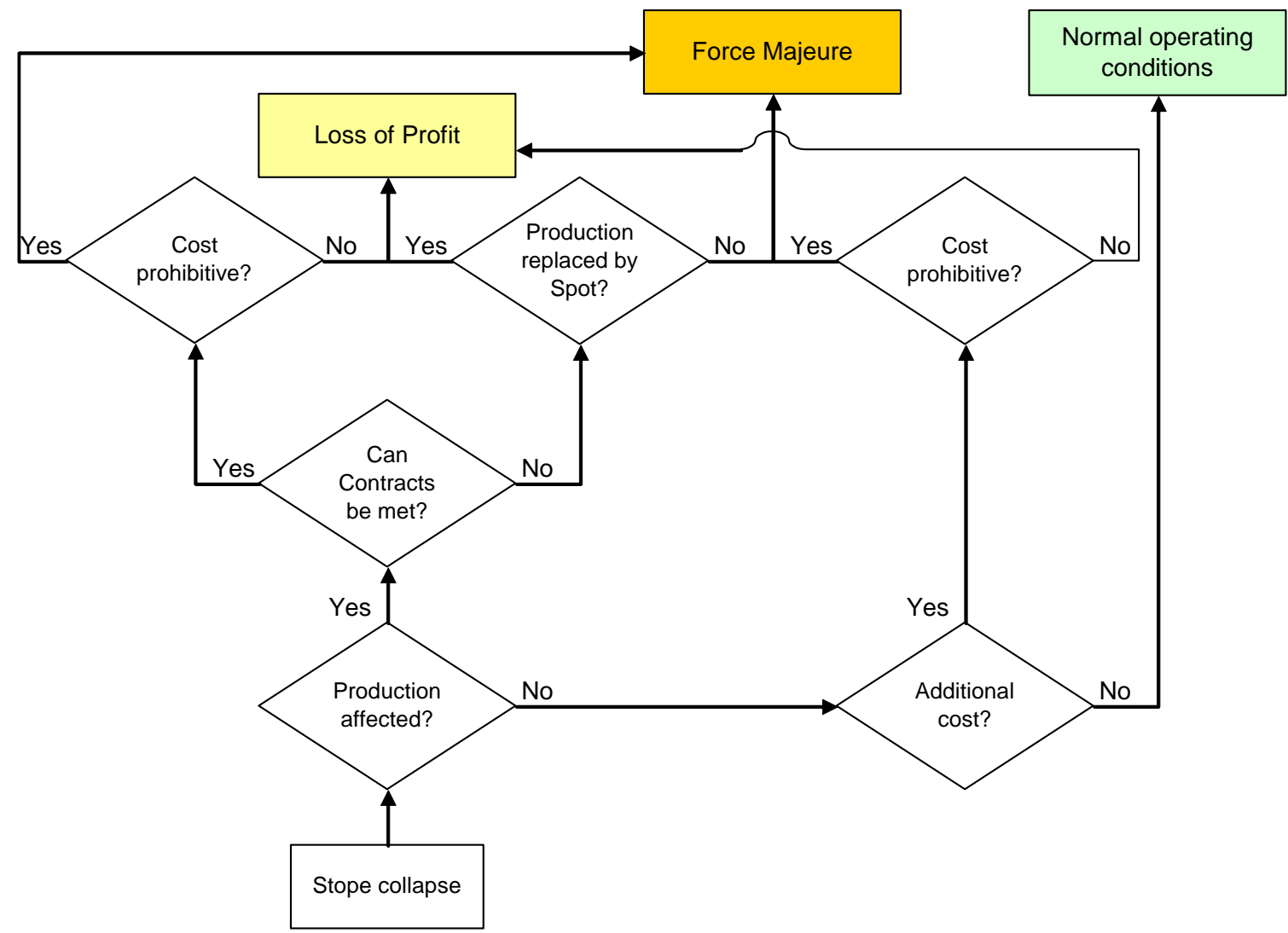

Figure 20 Event tree example for evaluation of economic consequences of failure (Terbrugge et al. 2006) 
The consequences of a collapse that need to be considered include: clean-up cost, removal of collapse material; stope rehabilitation; stope re-access; equipment redeployment; unrecoverable ore and dilution; damage to equipment and infrastructure; direct and indirect costs associated with fatalities and injuries; and disruption of production. Once these consequences have been quantified, the decision whether to accept the excavation and support designs is a management one, weighing up the economic risk character of the alternatives within the corporate risk profile. The outcome from this risk methodology process ensures that risks in the areas of safety, equipment damage, economic impact, force majeure, and industrial action and negative public relations are within the required criteria set by the mining executives.

The methodology involves the concept that stability is not the end objective but that safety is not compromised and that the economic impact of collapses has been optimised. Therefore, failures are acceptable on condition that they can be managed to ensure that the acceptable risk criteria are met. A further benefit is that the extent of rock engineering data required can be quantified, since the risk/consequence analysis process can be used to assess the impact of higher quality data on the consequences of failure.

One of the major advantages of using a risk approach is the ability to quantify the costs and benefits associated with the events. For example, additional or different types of support may be able to prevent a collapse, and the consequent savings from no loss of production will probably far exceed the support costs, therefore creating value for the mine. Value could also be created using effective stope monitoring and stope management procedures.

\section{Conclusion}

Several conclusions can be drawn from the content of this paper:

- In rock engineering design, it is most important to follow a logical design process. A suitable process has been described in the paper, and this can serve as a checklist to ensure that a robust and defensible design has been carried out, and that all aspects that should be taken into account in the design, are taken into account.

- It is most important to identify likely mechanisms of behaviour and rock failure. This particularly applies to unusual mechanisms that may lead to failure at unexpectedly low stress conditions. Rock failure criteria should correspond with failure mechanisms if successful prediction is to be achieved.

- Failure of rock is likely to involve several mechanisms as it develops, and these must be taken into account in design. Rock failure criteria applied must correspond with the failure mechanisms.

- Risk can be used as a rock engineering failure criterion. It takes into account the consequences of failure, and quantification of risk can identify the potential for substantial value creation in the mining operation.

\section{Acknowledgement}

The research by the author of this paper is supported in part by the National Research Foundation (NRF) of South Africa (Grant specific unique reference number (UID) 85971). The Grantholder acknowledges that opinions, findings and conclusions or recommendations expressed in any publication generated by the NRF supported research are that of the author, and that the NRF accepts no liability whatsoever in this regard.

\section{References}

Accreditation Board for Engineering and Technology 1987, Fifth annual report, ABET, Washington DC. Baecher, GB \& Christian, JT 2003, Reliability and statistics in geotechnical engineering, Wiley, West Sussex. Bieniawski, ZT 1988, 'Towards a creative design process in mining', Mining Engineering, vol. 40, pp. 1040-1044.

Bieniawski, ZT 1991, 'In search of a design methodology for rock mechanics', in J-C Roegiers (ed.), Proceedings of the 32nd US Symposium on Rock Mechanics, Rock Mechanics as a Multidisciplinary Science, CRC Press, Boca Raton, FL, pp. 1027-1036. 
Bieniawski, ZT 1992 'Principles of engineering design for rock mechanics', in JR Tillerson \& WR Wawersik (eds), Proceedings of the 33rd US Symposium, Rock Mechanics, CRC Press, Boca Raton, FL, pp. 1031-1040.

Dünner, C, Bigarré, P, Clément, C, Merrien-Soukatchoff, V \& Gunzburger, Y 2007, 'Natural and thermomechanical stress field measurements at the "Rochers de Valabres" Pilot Site Laboratory in France', in C Olalla, N Grossmann \& L Ribeiro e Sousa (eds), Proceedings of the 11th Congress of the International Society for Rock Mechanics, Taylor \& Francis Group, London, vol. 1, pp. 69-72.

European Standard 2004, EN 1997-1 Eurocode 7: Geotechnical Design - Part 1: General rules, European Committee for Standardization (CEN), Brussels.

Frith, R, Thomas, R, Hill, D \& Buddery, P 2002, 'Survey of horizontal stresses in coal mines from available measurements and mapping, final project report, no. COL802, prepared for the Safety in Mines Research Advisory Committee.

Germanovich, LN \& Dyskin, AV 2000, 'Fracture mechanisms and instability of openings in compression', International Journal of Rock Mechanics and Mining Sciences, vol. 37, pp. 263-284.

Hadjiabdolmajid, V, Kaiser, PK \& Martin, CD 2002, 'Modelling brittle failure of rock', International Journal of Rock Mechanics and Mining Sciences, vol. 39, pp. 731-741.

Hadjigeorgiou, J \& Stacey, TR 2013, 'The absence of strategy in ore pass planning, design and management', Journal of the South African Institute of Mining and Metallurgy, vol. 113, pp. 795-801.

Hambly, EC \& Hambly, EA 1994, 'Risk evaluation and realism, Proceedings of the Institution of Civil Engineers and Civil Engineering, vol. 102, pp. 64-71.

Hill, PH 1983, 'Techniques in teaching creative engineering design', Proceedings of the ASEE Annual Conference, American Society for Engineering Education, Washington DC.

Ilbury, C \& Sunter, C 2005, Games foxes play: planning for extraordinary times, Human \& Rosseau Tafelberg.

Joughin, WC \& Stacey, TR 2005, 'Risks associated with orepasses in deep level tabular mines based on historical pass performance', Journal of the South African Institute of Mining and Metallurgy, vol. 105, pp. 795-802.

Martin, CD, Read, RS \& Martino, JB 1997, 'Observation of brittle failure around a circular test tunnel', International Journal of Rock Mechanics and Mining Sciences, vol. 34, no. 7, pp. 1065-1073.

Nyungu, D 2013, 'Effect of time on the tensile strength of several Bushveld Complex rock types' Master of Science thesis, University of the Witwatersrand.

Ortlepp, WD \& Moore, MA 1987, 'Underground observation of high propagation-rate extension fractures', Proceedings of the 6th ISRM Congress, International Society for Rock Mechanics, vol. 2, pp. 1173-1180.

Philley, JO 1992, 'Acceptable risk-an overview', Plant/Operations Progress, vol. 11, no. 4, pp. 218-223.

Sahouryeh, E, Dyskin, AV \& Germanovich, LN 2002, 'Crack growth under biaxial compression', Engineering Fracture Mechanics, vol. 69, no. 18, pp. 2187-2198.

Stacey, TR 1981, 'A simple extension strain criterion for fracture of brittle rock', International Journal of Rock Mechanics and Mining Sciences \& Geomechanics Abstracts, vol. 18, no. 6, pp. 469-474.

Stacey, TR 2006, 'Design - a strategic issue', Proceedings of the 2nd International Seminar on Strategic versus Tactical Approaches in Mining, Section 4, $13 \mathrm{p}$.

Stacey, TR \& de Jongh, CL 1977, 'Stress fracturing around a deep level bored tunnel', Journal of the South African Institute of Mining and Metallurgy, vol. 78, no. 5, pp. 124-133.

Stacey, TR \& Rojas, E 2013, 'A potential method of containing rockburst damage and enhancing safety using a sacrificial layer', Journal of the South African Institute of Mining and Metallurgy, vol. 113, pp. 565-573.

Stacey, TR \& van Rooyen, C 2014, 'Problem 2: Prediction of fracturing and dynamic failure of the roof in tabular stopes in a platinum mine', problem submitted to the Mathematics in Industry Study Group, University of the Witwatersrand.

Stacey, TR \& Yathavan, K 2003, 'Examples of fracturing of rock at very low stress levels', Proceedings of the 10th International Society for Rock Mechanics Congress, South African Institute of Mining and Metallurgy, Johannesburg, vol. 2, pp. 1155-1159.

Stacey, TR, Terbrugge, PJ \& Wesseloo, J 2007, 'Risk as a rock engineering design criterion', in Y Potvin, J Hadjigeorgiou \& TR Stacey (eds), Challenges in Deep and High Stress Mining, Australian Centre for Geomechanics, Perth, pp. 17-23.

Stacey, TR, Wesseloo, J \& Bell, G 2005, 'Predicting the stability of rockpasses from the geological structure', Journal of the South African Institute of Mining and Metallurgy, vol. 105, pp. 803-808.

Steffen, OKH 1997, 'Planning of open pit mines on a risk basis', Journal of the South African Institute of Mining and Metallurgy, vol. 97, pp. 47-56.

Steffen, OKH \& Terbrugge, PJ 2004, 'Designing open pit slopes with risk', Proceedings of the Colloquium on the Management of Risk in the Minerals Industry, South African Institute of Mining and Metallurgy, Johannesburg, $10 \mathrm{p}$.

Tarasov, B \& Potvin, Y 2013, 'Universal criteria for rock brittleness estimation under triaxial compression', International Journal of Rock Mechanics and Mining Sciences, vol. 59, pp. 57-69.

Taylor, JG, Taylor, RN \& Hall, AE 1978, 'The introduction of a tunnel borer into a South African gold mine', Journal of the South African Institute of Mining and Metallurgy, vol. 78, pp. 188-198.

Terbrugge, PJ, Wesseloo, J, Venter, J \& Steffen, OKH 2006, 'A risk consequence approach to open pit slope design', Journal of the South African Institute of Mining and Metallurgy, vol. 106, no. 7, pp. 503-511.

Wesseloo, J 2000, 'Predicting the extent of fracturing around underground excavations in brittle rock', Proceedings of the South African Young Geotechnical Engineers Conference, South African Institution of Civil Engineering, $12 \mathrm{p}$.

Wilson, R \& Crouch, EAC 1987, 'Risk assessment and comparisons: an introduction', Science, vol. 236.

Wong, W 2002, How did that happen?: Engineering Safety and Reliability, Wiley, London. 